\title{
An Environment to Co-develop Informational Systems for IR in Japan
}

\author{
Tetsuya Oishi ${ }^{*}$, Masao Mori ${ }^{\dagger}$, Eiichi Takata ${ }^{\ddagger}$
}

\begin{abstract}
Most universities around the world must be accredited in order to assure and enhance the quality of education. Japanese universities also are under accreditation by the government as well. They must undergo certified evaluation and accreditation periodically, which is conducted by organizations certified by the Japanese Minister of Education. Accreditation committees evaluate every university based on the Standards for Evaluation and Accreditation by reviewing the self-assessment reports. That is why it is important for universities to pursuit their advantages and to create high quality self-assessment report. To present some advantages in the report, the university staffs have to obtain the evidences demonstrating some effects or outcomes. Moreover, Institutional Research (IR) is one of the important tools to obtain these evidences. Some systems for IR have been developed individually, but few of them were shared or co-developed with other universities. If many universities in Japan can utilize such systems, we can obtain various knowledges newly. In this paper, we explain not only some advantages of sharing or co-developing systems but also some problems.
\end{abstract}

Keywords: Institutional Research, Co-development System

\section{Background}

In recent year, many constituent members of Japanese universities think that IR is very important tool for their universities. IR helps universities to decide something about the management, the educational method, and so on. So, in Japan, IR organizations have been created in many universities.

An institute for IR has been set up in Japan since 2012 (Figure 1). Nine universities have joined this institute. These universities consist of one mainstay university ( $\mathrm{X}$ university) and eight cooperative universities (A, B, ..., H university). Basically, the mainstay university leads other eight cooperative universities. Figure 1 shows not only that nine universities cooperate each other but also that the mainstay university provides the cooperative universities something for IR. The purposes of the institute are as follows.

\footnotetext{
* Kyushu University, Fukuoka, Japan

$\dagger$ Tokyo Institute of Technology, Tokyo, Japan

* Kyushu University, Fukuoka, Japan
} 


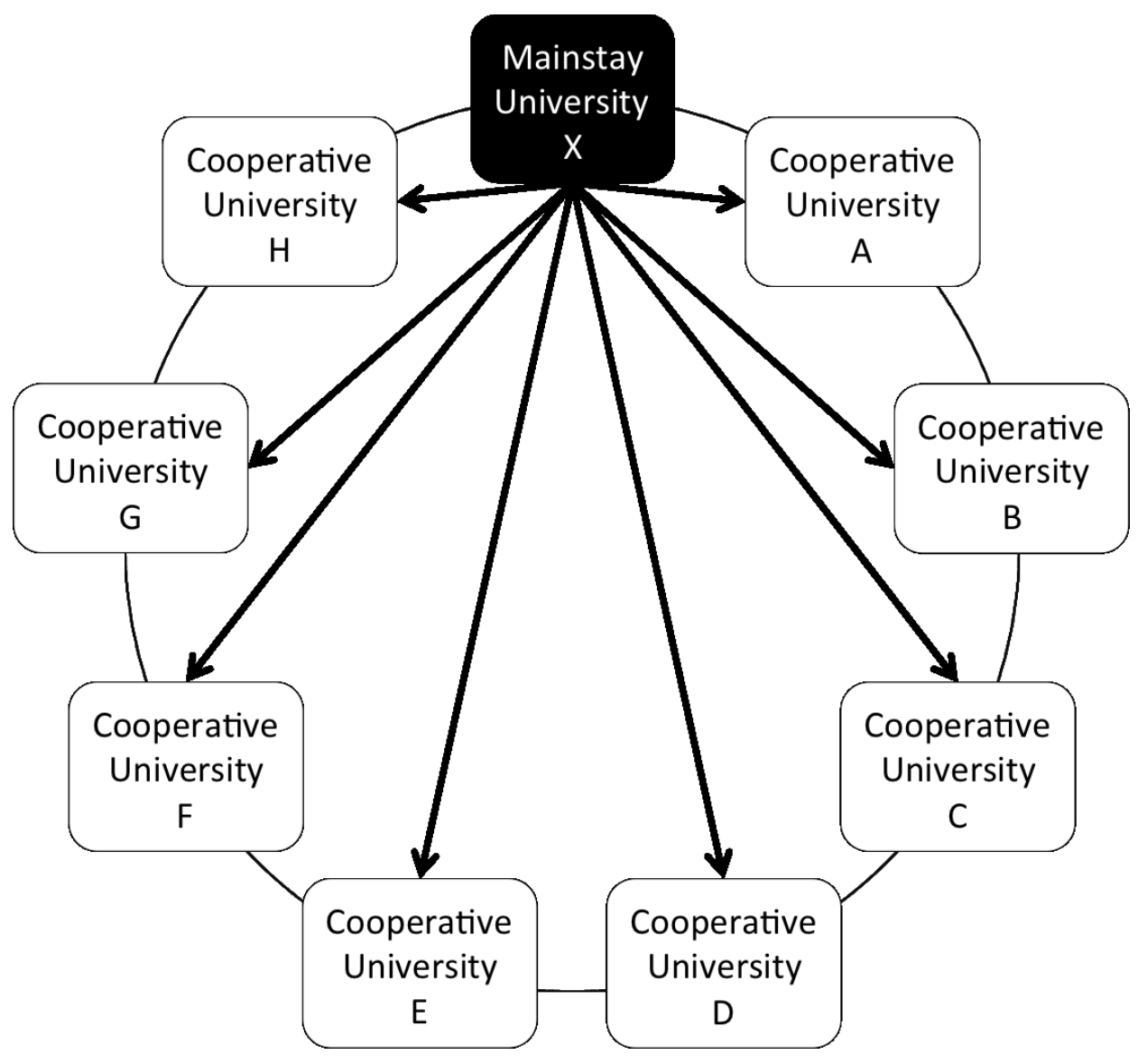

Figure 1: An Institute for IR in Japan

- Co-training talented persons for IR.

- Co-developing common informational systems.

- Co-developing skills for informational analysis and application.

- Strengthening IR functions around the cooperative universities.

Especially, in order to co-develop common informational systems, we had to introduce an environment to be able to develop from each universities. IR needs many data to show the present situations of universities. Then, to gather these data, informational systems are necessary. So, we had introduced a cloud system[1] to use virtual machines. The virtual machine is a software to emulate an operation of a computer. This technology is important for co-development.

If the staffs of a certain university develop an informational system independently, they monopolize the know-how of developing system. If the staffs of some universities codevelop an informational system, they can share the know-how of it. This is the merit of codevelopment. To co-develop some systems, we have to prepare a server machine. We can prepare the server machine by using the cloud system easily.

For example, we assume that a certain university needs an informational system. First, the staffs in the university have to decide a specification of the system. After the spec- 
ification of hardwares is fixed, they actually have to obtain hardwares such as personal computers or server machines. Generally, they need many money in order to purchase these hardwares. If the cost is too expensive to buy them, they sometimes have to give up developing the system after considering cost-effectiveness. It is unhappy for the university not to develop the system.

The problem mentioned above is not to be able to purchase hardwares. The staffs of the university will be happy that they can obtain these hardwares freely. However, someone can not purchase these hardwares for the university. In the case of our institute, the mainstay university had installed the environment. So, the mainstay university can provide virtual machines for the cooperative universities. The staffs of the university which is given a virtual machine can start developing information systems easily. Then, the cooperative universities became to be able to use the environment technically.

Until now, there were the cases that many universities or educational institutes could use a common system. But there are no cases that these institutes could co-develop systems to co-use. So we introduced the environment to co-develop common systems. Even if the environment is available technically, it is difficult to use it actually. In this paper, we show the difficulty of managing the environment for co-developing. In the rest of this paper, we show the related works in Section 2. Next, we explain the problems for management of co-developing environment in Section 3 and their solutions in Section 4. Finally, in Section 5 , we conclude our paper.

\section{Related Works}

\subsection{Netherlands}

In Netherlands, the Internal Quality Assurance (IQA) in universities is the most important matter [2]. IQA is a process that higher education institutions themselves take responsibility for checking and evaluating their various activities. In order to evaluate education, IQA is one of themes for accreditation. There are three standards requesting each universities for IQA as follows.

- Periodical evaluation

- Method for improvement

- Involvement of staffs of school, reunions, and special fields

It is very important that these actors are concerned with IQA. Moreover, in order to evaluate research, not only an external evaluation is conducted once in 6 years, but also an internal evaluation is conducted once in 3 years.

There is a group for IR in Netherlands. This group is called DAIR (Dutch Association for Institutional Research). The main purposes of DAIR are to develop ability for IR and to promote IR activities. Various staffs of school can make a network of IR. Then they can solve the problems that each university can't solve.

There is a database system for researchers which name is METIS. The merit of METIS is that it is not necessary to unify the data scheme by using a same database system. METISs are operated separately. So, KNAW (Koninklijke Nederlandse Akademie van Wetenschappen: Royal Netherlands Academy of Arts and Science) made plan for unification of the database system for research. As a result, KNAW constructed a unified database system 
NARCIS (National Academic Research and Collaborations Information System) in 2007. The method for gathering data "harvesting" is used in NARCIS. NARCIS is operated as a hub system for research information in Netherlands.

In Netherlands, the nation operates IR of all universities. However, in Japan, there are not any institutions. So, we have established a small institution which consists of nine universities. We wish that whole Japanese universities join this institution and cooperate each other.

\subsection{United States of America}

In United States of America, various examinations are conducted by using standardized data [3]. Before students enter a university, they are examined not only the grade of test but also their profiles. The profiles contain their characteristics, interests, needs, plans after entering university, and so on.

Moreover, after they enter a university, they are also examined. Especially, the standardized multipurpose questionnaires for university students are conducted at UCLA (University of California, Los Angeles). For example, CIRP (Cooperative Institutional Research Program) or NSSE (National Survey of Student Engagement) are conducted by Higher Education and Student Research Center of UCLA. Each university which is using the examination is charged. Instead of charging, the data obtained from each university can be compared with each other.

After graduating university, the students are also examined. For example, this examination is conducted by COFHE (Consortium on Financing Higher Education). This consortium can exchange the data obtained from each university. In Association of America Universities, each university can also exchange such data.

The universities in USA examines students by various methods. They share data obtained from students by using common tools. So the data from each universities is managed systematically in USA.

In USA, IR is very popular. However, IR has just started in Japan. We require the standards for IR of Japan. So, the case of USA is very useful. We wish that our institution can show the Japanese standards for IR.

\subsection{Japan}

The IR consortium is established in Japan [4]. This consortium has a system for automatic bench marking. Four universities are cooperating on IR consortium. This system named IRiS (Institutional Research Information System). IRiS is one of the database systems by cloud service. So, the universities that use this system need not to prepare own servers to work this database. The staffs in each university gather the data from various questionnaires for students, and upload them to IRiS.

IRiS can show not only tables created by the gathered data but also various graphs such as a vertical bar chart, horizontal bar chart, pie chart, and so on. These tables or graphs are shared among cooperative universities. Then, the universities can confirm the present situation by comparing mutually. They can also confirm the change over the years.

IR consortium is different from our institute. While they have IRiS to do bench marking, we have IR cloud to co-develop system. If they are fused, something good may be produced. Japan is in transition period about IR. So, there are some groups for IR. 


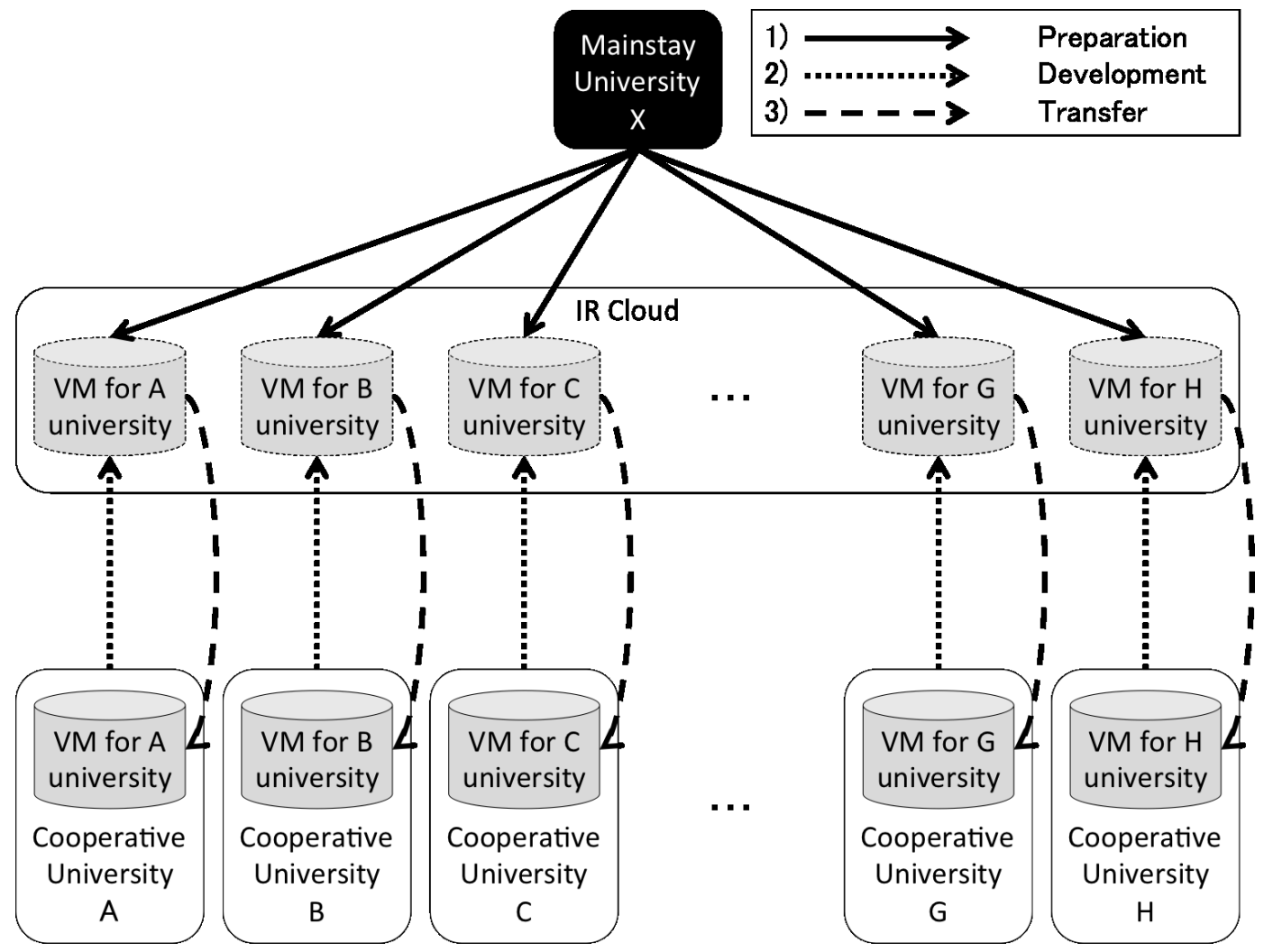

Figure 2: Co-development

\section{Problems in Co-development}

In this section, we show the abstract of co-development in our institute. Then, we explain the problems at both the mainstay university and the cooperative universities.

\subsection{Co-development}

In our institute, the mainstay university has already introduced the environment for utilizing virtual machines (VMs). We call this environment "IR cloud". Our plan to use IR cloud is as follows.

1. First, the mainstay university prepares VMs for the cooperative universities.

2. Then, the cooperative universities develop some informational systems by using VMs given.

3. After developing the systems, the mainstay university extracts the VMs and transfers them to other environment that the cooperative university operate themselves.

In Figure 2, we show the image of co-development. We explain each process in detail as follows. 


\subsubsection{Preparation}

We can prepare VMs easily by using IR cloud. First, we have to decide some items as follows:

- Sort of operating system

- Size of hard disk drive

- Size of random access memory

- Number of CPU cores

Only we have fixed these items, we can prepare VMs. However, the VMs are used locally. In other words, the staffs in mainstay university can use VMs, but the staffs in cooperative universities can not use VMs. How can the cooperative universities' staffs use these VMs? We have to let these VMs be used globally. First, we assign global IP addresses to these VMs. Also, we have to permit VM to be accessed through some port. For example, 22 (for secure shell), 80 (for hypertext transfer protocol), and so on are usually used. After we have set them up, the cooperative universities' staffs become to be able to use VMs at each campus technically. The VMs can be prepared in a half hour at the longest.

\subsubsection{Development}

After preparing VMs, the cooperative universities' staffs can start developing individually. They are not required any money to purchase hardwares because there are VMs. These VMs can be prepared in a short time. Then, the staffs can start developing some informational systems when they would like to do so. If someone creates a sample system in a VM, the staffs only customize the system. The ease of starting developing is very important.

I assume that there is a general-purpose system such as a system for storing achievements for teachers. This system may has the minimum requirements for all universities. But these universities also have special requirements of this system. Then, the staffs of these universities have to customize this system. These process is realized easily by using IR cloud.

For example, the mainstay university has a web system to manage the mid-term plan for the university actually. This system has been operated in several years. Then, the staffs in one of cooperative universities thought that they would like to use this system. We prepared the web system for the university and they had a trial of it. After using it, they decided to introduce it to their university. Using IR cloud, the members of our institute for IR can have a trial and introduce every web system. If a web system to analyze data such as IRiS is created in IR cloud, we can also use it. To achieve IR, we need various web systems. So, IR cloud, which can be used by the members of our institute, is very useful system for IR.

\subsubsection{Transfer}

The cooperative universities' staffs can use IR cloud for development of informational systems in VMs. In other words, they can not let VMs operate for each university in IR cloud. So, if they would like to use the system developed in IR cloud, the system have to be transferred to each university's environment. VMs can be extracted from IR cloud easily. In each university, the staffs only import the extracted VM into their own environment. Then, the system becomes to be available in own environment. 
As mentioned above, we have an environment to co-develop some informational systems. That is to say, our environment is different from the works explained in Section 2. While some universities co-use a common system in these works, our activity is focused on co-developing. In our co-developing environment, there are many merits technically, but there are some problems caused by not technical matters. In next sections, we mention the problems at mainstay university and cooperative universities.

\subsection{Problems at Mainstay Univerisity}

In our activity, the mainstay university has the environment to co-develop some systems. We explain a problem when we would like to release a web system.

\subsubsection{Port}

(Figure $3 \mathrm{~B} 1$ ) In order to release a web system, it is enough that the port 80 can be used in each hardware usually. Generally, web systems are provided through port 80 . However, in the mainstay university, a web system can not be released after only the port 80 becomes to be available. The reason is that the mainstay university has a firewall which shuts out any access from the port 80 .

\subsubsection{IP address}

(Figure 3 B2) Web systems have global IP addresses generally. All browsers can specify web systems by IP addresses. In our activity, the IP address is given from the mainstay university because there is the server at the university. In this case, the cooperative universities uses the global IP addresses given by the mainstay university. Generally, it is not desirable that an IP address owned by one university is used by other university. In the mainstay university, there is a rule that the global IP addresses given by mainstay university can not provided to other universities.

Thus, while our activity is effective technically, some inter-university problems exist. We will mention how to solve these problems later in Section 4.

\subsection{Problems at Cooperative Universities}

We assume that some problems occurred in the mainstay university were solved. In this situation, we mention the problems that may occurred in the cooperative universities.

\subsubsection{Skill}

(Figure $3 \mathrm{C} 1$ ) If there are the staffs who can develop the informational systems, there are no problems. But, there may not be such staffs in all cooperative universities. Then, these cooperative universities' staffs can not start developing.

\subsubsection{Security}

(Figure $3 \mathrm{C} 2$ ) In each university, security policies are established. Based on this policies, they may not be able to develop some systems using the co-developing environment. Even if there are good environments to co-develop, it is meaningless in this condition. 


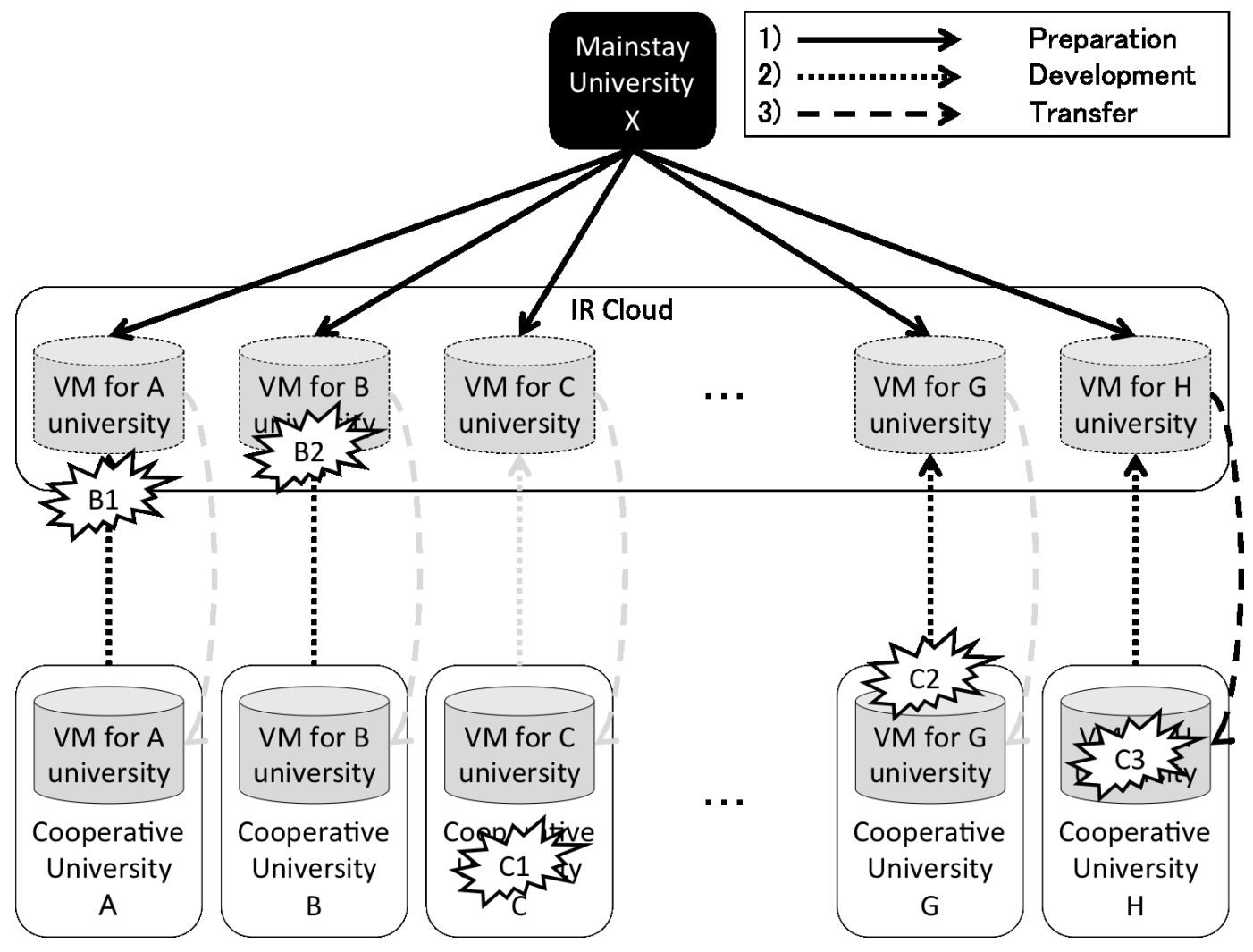

Figure 3: Problems

\subsubsection{Cost}

(Figure 3 C3) The cooperative universities need not to be required the cost to prepare an environment to develop an informational system. However, it is necessary that they prepare the machine or the environment to operate the system co-developed. Thus they need expense for it.

\section{Solutions}

As mentioned above, there are some problems to co-develop the informational systems. In this section, we consider some solutions against the problems.

\subsection{Common solutions}

When our institute decided to introduce the environment for co-development, we didn't have enough time to discuss the plan with cooperative universities. So, various problems occurred later. We had to pre-consider that the activity was not the work that only one university had to do. If you would like to construct such inter-university systems, all cooperative universities have to cooperate with each other. 


\subsection{Solutions from Mainstay University}

The mainstay university has to prepare the co-developing environment that the cooperative universities' staffs can use easily. They should be able to access the environment at the least from the cooperative universities. The problems we mentioned in Section 3.2.1 and 3.2.2 bring some bad effects for co-developing.

In order to solve them, it is important to confirm the security policy of this university firstly. There is a section that manages network and information in each university. The security policy is established by such a section usually.

Next, if the policy restricts us from using ports and IP addresses in other universities, we have to negotiate with the section managing the policy about the permission of using them. Then we have to prepare a powerful reason to use them. For example, the reason should include costs, convenience, effects, and outcomes, which are worth permitting us to use them. The inadequate reason will be rejected. There are easy operations to let the ports or IP addresses be used from other universities. So, it is significant to obtain permissions of them.

\subsection{Solutions from cooperative Universities}

While the mainstay university has completely prepared the environment of co-development, it is meaningless if the cooperative universities can not use it. First, the staffs who can use it have to be trained to solve the problem as mentioned in Section 3.3.1. However, there are a few people who are suitable for using it. It is important that such people can rotate among the cooperative universities. Then the co-developing environment will be able to show the efficiency.

Next, the cooperative universities also should have security policies as mentioned in Section 3.3.2. If the policy prevents from using the co-developing environment, they have to make an effort to prepare the condition to use it.

The most significant problem is the cost to prepare the environment to operate the codeveloped system as mentioned in Section 3.3.3. To prepare a real machine for operating virtual machines is very expensive. But on the other hand, preparing a cheap machine, in which a free virtualization software can be working, is not suitable for using co-developed system. In recent years, there is a public cloud. The systems developed in virtual environment can be deployed in the public cloud. Moreover, the fee is not expensive for using it.

\section{Conclusion}

In our institute, we introduced the virtual environment for co-developing the system with cooperative universities. However, we have some problems to be solved when using the environment. As mentioned in Section 4, we showed some proposals to solve the problems. The security policy and the cost are bottlenecks of our introduction especially. So, we have to adjust the differences of opinion among the mainstay university and the cooperative universities.

Our environment is very efficient to co-develop the systems with various universities if some problems are solved. We advise that pre-discussion is very important when introducing the environment for co-developing. Also we expect that a lot of universities can introduce such a environment. 
In future work, we would like to co-develop by using the environment actually after solving some problems. Our environment for co-development will be sure to contribute to the filed of IR. IR has been penetrated in Japan. However, there are various informational systems for IR. Moreover, there are no environments to co-develop informational systems except for our environment. If you are interested in this environment, why don't you introduce it?

Finally, this work was supported by JSPS KAKENHI Grant Number 15K04305.

\section{References}

[1] Tetsuya Oishi, Masao Mori, Toshie Tanaka, and Eisuke Ito, "Cooperative Development and Individual Operation for Information Systems of IR in a Virtual Environment", 2nd International Conference on Institutional Research and Institutional Management (IRIM 2013), 2013

[2] Takuo Kominato, Hotoshi Sato, Masao Mori, and Eiichi Takata, "The role of IR in Dutch universities - contribution to internal quality assurance", Japanese Association of Higher Education Research, 2009

[3] Masyuki Kobayashi, "Gathering, analysis, and IR of students' information in USA", Between 2012 February and March, pp.22-23, 2012

[4] "IR consortium", http://www.irnw.jp/ (accessed 17th February, 2015). 